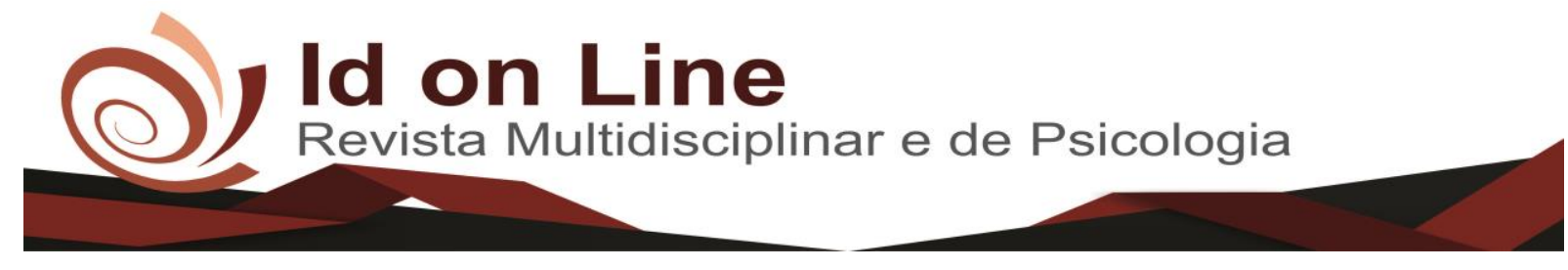

DOI: 10.14295/idonline.v13i47.2079

Artigo

\title{
Percepção dos Enfermeiros da Atenção Primária diante da Violência Contra a Gestante
}

\author{
Julliany Larissa Correia Santos ${ }^{1}$, João Victor Silva Rodrigues ${ }^{2}$, Claudia Daniele Barros Leite Salgueiro ${ }^{3}$, \\ Cláudia Fabiane Gomes Gonçalves ${ }^{4}$, Taysa Vieira Almeida ${ }^{5}$, Gladyanny Costa Veras Soares ${ }^{6}$
}

\begin{abstract}
Resumo: Objetivo: Conhecer como os profissionais da Estratégia de Saúde da família reconhecem e enfrentam o fenômeno da violência contra as gestantes. Método: Estudo descritivo e de abordagem qualitativa, composto por Enfermeiros do município de Pesqueira, Pernambuco, por meio de entrevista semiestruturada. A análise dos dados foi feita através da técnica da análise de conteúdo unida a uma pesquisa documental no Sistema de Informação de Notificação de Agravos. Resultados: Apesar de grande parte dos Enfermeiros terem visto o tema violência na graduação, e alguns já participaram de curso ou palestra que abordassem a temática, ainda é incipiente o enfrentamento deste profissional diante dos casos de violência contra a gestante, umas vez que grande parte destes profissionais não reconhecem todas as tipologias da violência, não se sentem capazes em realizar a notificação por medo de sofrerem represálias e tem escasso conhecimento sobre o trabalho em rede. Conclusão: Destaca-se a necessidade de sensibilizar e qualificar os profissionais a identificar e abordar qualquer tipo de violência promovendo educação em saúde no intuito de instruir as gestantes, empoderando este público para evitar a recorrência e o reflexo deste fenômeno em suas vidas.
\end{abstract}

Descritores: Saúde Pública; Enfermagem; Violência; Gestantes.

\section{Perception of Primary Care Nurses regarding Violence Against Pregnant Women}

\begin{abstract}
Objective: To know how the professionals of the Family Health Strategy recognize and face the phenomenon of violence against pregnant women. Method: A descriptive and qualitative study, composed by Nurses of the municipality of Pesqueira, Pernambuco, through a semi - structured interview. The analysis of the data was done through the technique of content analysis linked to a documentary search in the Notification of Injury Information System. Results: Although most of the nurses have seen violence in the undergraduate course, and some have already participated in a course or lecture that approached the subject, it is still incipient the confrontation of this professional in the cases of violence against the pregnant woman, since a large part of these professionals do not recognize all types of violence, do not feel able to make the notification for fear of reprisals and have little knowledge about network work. Conclusion: It is necessary to raise awareness and qualify professionals to identify and approach any type of violence by promoting health education in order to instruct pregnant women, empowering this public to avoid recurrence and reflection of this phenomenon in their lives.
\end{abstract}

Descriptors: Public health; Nursing; Violence; Pregnant women;

\footnotetext{
${ }^{1}$ Instituto Federal de Educação, Ciência e Tecnologia de Pernambuco, Campus Pesqueira. jullianyif@ gmail.com;

${ }^{2}$ Enfermeiro pelo Instituto Federal de Pernambuco, Campus Pesqueira. Tecnólogo em Gestão Hospitalar pela Universidade

Norte do Paraná. victorodrigues.ifpe@ gmail.com;

${ }^{3}$ Instituto Federal de Educação, Ciência e Tecnologia de Pernambuco, Campus Pesqueira.

claudia.leite@pesqueira.ifpe.edu.br;

${ }^{4}$ Instituto Federal de Educação, Ciência e Tecnologia de Pernambuco, Campus Pesqueira

claudia@pesqueira.ifpe.edu.br;

${ }^{5}$ Instituto Federal de Educação, Ciência e Tecnologia de Pernambuco, Campus Pesqueira. taysaxto@ hotmail.com;

${ }^{6}$ Enfermeira, Especialista em Obstetrícia e Saúde Pública, Auriculoterapeuta, Reikiana, é Enfermeira na UBSF Severiano de Brito Freire em Arcoverde, atua na assistência ao parto domiciliar planejado, e docente da Autarquia de Ensino Superior de Arcoverde (AESA) da disciplina de Obstetrícia. gladyanny@ hotmail.com.
} 


\section{Introdução}

A violência pode ser percebida como o intencional uso da força física, em ameaça ou real, contra si próprio ou a outra pessoa, contra um grupo ou comunidade, que resulte ou tenha probabilidade de resultar em ofensa, morte, dano psicológico, privação ou prejuízos no desenvolvimento da pessoa. ${ }^{1}$

Na perspectiva do gênero, a violência é uma relação social imersa em disputas de poderes que assume múltiplas faces na sociedade. Considera-se violência contra a mulher (VCM): todos os atos ou comportamentos que, por meio de ameaça, coerção, força ou intimidação, infringem às mulheres danos morais, psicológicos, físicos ou sexuais, seja na vida privada ou pública, atingindoas em sua integridade física e subjetiva ${ }^{2}$.

As configurações da violência contra a mulher reúnem: a violência física, que compreende qualquer conduta que ofenda a integridade ou a saúde corporal das mulheres; a violência psicológica, que inclui as ameaças, humilhações, isolamento, perseguição, entre outros; a violência moral caracteriza-se por calúnias, difamações e injúrias; a violência patrimonial se concretiza por roubo, retenção ou danos aos bens materiais, recursos e documentos; e a violência sexual, caracteriza-se por relações sexuais não desejadas, práticas sexuais não consentidas e pelo impedimento do uso de contraceptivo. ${ }^{3,1}$

Dados do Sistema de Informações sobre Mortalidade (SIM) evidenciam que no ano de 2016, ocorreram 26.806 casos de óbitos de mulheres por causas externas (acidentes, violência), sendo 6.917 apenas na região nordeste e 1.253 em Pernambuco. Demonstra que a mortalidade de mulheres ainda é alta, carecendo de ações e serviços mais efetivos, que minimizem tais discrepâncias de gênero entre homens e mulheres diminuindo assim sua vulnerabilidade. ${ }^{4}$

Este fenômeno pode estar presente nos diferentes âmbitos da vida da mulher. Nesta perspectiva, pode-se apontar a ocorrência da violência em um período em que seu bem-estar deveria ser especialmente assegurado: a gestação.

A violência obstétrica (VO) é definida como uma apropriação do corpo feminino e de sua autonomia reprodutiva, durante o processo do pré-parto, parto e pós-parto, pelos profissionais da área da saúde, expondo a mulher a condutas desumanizadas, à utilização de procedimentos dolorosos ou constrangedores, bem como a utilização de métodos farmacológicos sem indicação, convertendo o processo natural de nascimento em patológico, e uso de atitudes abusivas no que tange ao psicológico feminino. ${ }^{5}$

1203 Id on Line Rev. Mult. Psic. V.13, N. 47 p. 1202-1219, Outubro/2019 - ISSN 1981-1179 Edição eletrônica em http://idonline.emnuvens.com.br/id 
A violência contra a mulher na gravidez constitui um problema com um maior agravo devido ao elevado risco de morbimortalidade materna e neonatal. Um estudo realizado pela Organização Mundial da Saúde (OMS) evidenciou que a prevalência de violência por parceiro íntimo (VPI) na gestação pode variar de 1 a $28 \%$ entre países. ${ }^{6}$ Outro estudo semelhante realizado no Brasil, constatou que $8 \%$ das mulheres da cidade de São Paulo e $11 \%$ das mulheres da zona rural de Pernambuco relataram ter sofrido alguma forma de violência na gestação. ${ }^{7}$

A violência no período gestacional associa-se a consequências para o recém-nascido, como aborto espontâneo, parto prematuro, sofrimento fetal e baixo peso ao nascer, além de contribuir para a morbimortalidade feminina. ${ }^{3,8}$ Diante dos dados citados faz-se necessário melhorar a rede de assistência para o enfrentamento deste fenômeno por parte das vítimas, a fim de promover uma atenção voltada para seu empoderamento e adoção de estratégias para reconhecer e intervir nos casos e dar o apoio necessário às vítimas. ${ }^{9,10}$

No que tange a legislação brasileira, somente em agosto de 2006, foi criada a Lei Maria da Penha No 11.340/2006, adotando mecanismos para coibir a violência doméstica e familiar contra a mulher, eliminando todas as formas de discriminação, na tentativa de prevenir, punir e erradicar a violência contra a mulher em seus diferentes contextos. ${ }^{11}$

Já em março de 2015, foi sancionada a Lei do Feminicídio no 13.104/2015 que corrobora para o enfrentamento da VCM, prevendo esta como crime hediondo. ${ }^{12}$

Atenção Básica de Saúde, representada pela Estratégia Saúde da Família (ESF), é reconhecida como um espaço propício para acolher mulheres em situação de violência de gênero, pelo fato de que este modelo de atenção tem o vínculo como base da relação profissional/usuário e trabalha com adscrição da população no território. ${ }^{13}$

$\mathrm{O}$ cuidado de enfermagem às vítimas de violência deve ser planejado para promover segurança, acolhimento, respeito e satisfação de suas necessidades individuais. Refletir sobre o planejamento, pautado nos instrumentos básicos de enfermagem, nas políticas públicas de saúde e na legislação vigente, é fundamental para a proteção das vítimas e prevenção de agravos futuros. ${ }^{14}$

Um estudo realizado em 2015 mostrou que os enfermeiros não se sentem preparados diante do fenômeno da violência e relatam dificuldades para seu enfrentamento. Percebeu-se também uma grande resistência desses profissionais para notificarem os casos suspeitos, principalmente por terem medo de sofrer represálias. ${ }^{15}$

Neste sentido, o presente trabalho objetivou conhecer, como os profissionais da ESF, reconhecem e enfrentam o fenômeno da violência contra as mulheres grávidas. Este estudo se faz pertinente, pois servirá de arcabouço teórico para implementação das políticas públicas, a fim de 
minimizar a problemática da violência na gestação e instigar a produção de novos estudos a respeito do tema.

\section{Métodos}

Trata-se de um estudo descritivo e de abordagem qualitativa. O estudo descritivo determina as características e comportamento da população, além de identificar uma correlação entre as variáveis existentes. ${ }^{16}$ A escolha da abordagem qualitativa partiu da necessidade de compreender a lógica dos processos sociais pouco conhecidos alusivos a determinados grupos e proporcionar a elaboração de novos conceitos e hipóteses no decorrer da pesquisa. ${ }^{17}$

O estudo foi desenvolvido no município de Pesqueira que possui 62.931 habitantes, distante a $215 \mathrm{~km}$ da Capital Pernambucana situada na Microrregião do Vale do Ipojuca e Mesorregião do Agreste Pernambucano. ${ }^{18}$ Dados obtidos no Cadastro Nacional dos Estabelecimentos de Saúde do Brasil (CNES) apontam que o município possui 51 estabelecimentos de saúde para atender a população. ${ }^{19}$

A Rede do Sistema Único de Saúde (SUS) de Atenção Primária à Saúde de Pesqueira é composta por 18 equipes de Saúde da Família, correspondendo a 87\% de área coberta no município. Está em fase de planejamento a implantação de mais 4 equipes de Saúde da Família. Dentre as supramencionadas ESF, 13 estão situadas na área urbana e 5 na área rural do município.

A amostra se deu pelo método de conveniência, o que consiste em selecionar uma amostra da população que seja acessível, a mesma foi composta com os Enfermeiros das ESFs da zona urbana do município que aceitaram participar da pesquisa voluntariamente e concordaram em assinar o Termo de Consentimento Livre Esclarecido (TCLE), e atuassem no serviço há, pelo menos, seis meses. Foram excluídos os profissionais que estavam em gozo de férias, licença médica ou prêmio, no período da coleta, totalizando uma amostra total de 13 Enfermeiros.

A coleta dos dados foi desenvolvida entre os meses de Abril a Junho de 2018, por meio de entrevista semiestruturada formada por quatro perguntas subjetivas. As entrevistas ocorreram de forma individual, com auxílio de um gravador, a fim de garantir a fidedignidade, a partir de então as respostas foram transcritas assegurando a confiabilidade dos dados. 
A análise dos dados foi feita pelo método de Bardin, através da análise de conteúdo, modalidade temática compreendida como um conjunto de técnicas de análise das comunicações, que utiliza procedimentos sistemáticos e objetivos de descrição do conteúdo das mensagens com o intuito de fazer a inferência de conhecimentos relativos às condições de produção que recorre a indicadores. ${ }^{20}$

As respostas aos questionários foram transcritas em arquivo eletrônico do editor de texto Word e posteriormente inseridas em quadros. As respostas foram indexadas no Software ATLAS TI 8.0, versão Free onde agruparam-se 5 códigos e a partir de então foram formadas 3 eixos temáticos para a discussão do estudo. Para assegurar o anonimato dos sujeitos participantes da pesquisa enumerou-se através de códigos compostos pela vogal E, de Enfermeiro, seguida de números ordinais de $1,2,3 \ldots$.

Para caracterização geral do grupo dos enfermeiros da Atenção Básica (AB), da zona urbana de Pesqueira-PE, a pesquisa buscou identificar a idade, a titulação, tipo de especialização profissional, sexo, tempo de formação e tempo de atuação no serviço. Em relação ao tema violência buscou-se verificar se o tema foi abordado na graduação e se os sujeitos da pesquisa já participaram de cursos ou palestras sobre enfrentamento da violência contra a gestante.

Posteriormente seguiu-se com uma pesquisa documental, que é desenvolvida com base em material previamente elaborado e vale-se de dados que ainda não receberam tratamento analítico, ou que podem ser reelaborados de acordo com os objetos da pesquisa. Além de analisar dados primários, aqueles já processados podem receber outras interpretações. ${ }^{21}$

Os dados foram coletados no Sistema de Informação de Notificação de Agravos de Notificação (SINAN), que elenca uma série de doenças e agravos de notificação compulsória, entre eles a violência e suas diversas formas. Todo e qualquer atendimento de casos suspeitos ou confirmados de violência, quer seja em serviços de atenção primária ou terciária, deve ser registrado. O SUS tem seus dados disponibilizados gratuitamente, desde 1991, através do Departamento de Informática do SUS (MS/DATASUS). Esse órgão tem a responsabilidade de consolidar os dados alimentados pelas secretarias municipais e estaduais de saúde, bem como pelos estabelecimentos assistenciais conveniados. ${ }^{22}$

O estudo foi apreciado pelo Comitê de Ética em Pesquisa (CEP) Instituto Federal de Pernambuco - IF Sertão com parecer favorável sob número 2.010.131. Por conseguinte, atende aos princípios éticos da pesquisa com seres humanos, estabelecidos pelo Conselho Nacional de Saúde, através da Resolução 466/12 que exige que se obedeça aos quatro princípios éticos das pesquisas que envolvem seres humanos. ${ }^{23}$ 


\section{Resultados}

\section{Perfil sócio demográfico}

Dos 13 profissionais pesquisados, 38,50\% estão na faixa etária de 30 a 40 anos e 30,76\% entre 20 e 30 anos, configurando uma amostra predominantemente jovem. Quanto à titulação $84,62 \%$ declaram possuir algum tipo de especialização, dentre os tipos, a mais referida foi a de saúde coletiva com 53,85\%. Essa variável ultrapassou os $100 \%$, pois muitos usuários da amostra referiram ter mais de um tipo de especialização.

No que se diz respeito ao sexo, 100\% eram do sexo feminino. Na variável tempo de formação, 38,50\% dos enfermeiros concluíram a graduação nos últimos 3 a 5 anos. Quanto ao tempo de atuação no serviço 38,50\% atuam de 1 a 3 anos e 23,07\% atuam de 5 a 10 anos na $\mathrm{AB}$. Conforme mostra na tabela I.

Tabela I: Caracterização dos sujeitos da amostra

\begin{tabular}{llc}
\hline Idade (anos) & N & \\
$20-30$ & 4 & $30,76 \%$ \\
$30-40$ & 5 & $38,50 \%$ \\
$40-50$ & 3 & $23,07 \%$ \\
$50-60$ & 1 & $7,69 \%$ \\
Total & $\mathbf{1}$ & $\mathbf{1 0 0 \%}$ \\
& $\mathbf{3}$ & \\
Titulação & & $7,69 \%$ \\
Graduação & 1 & $84,62 \%$ \\
Especialização & 1 & $7,69 \%$ \\
& 1 & $\mathbf{1 0 0 \%}$ \\
Mestrado & 1 & \\
Total & $\mathbf{1}$ & \\
& $\mathbf{3}$ & $53,85 \%$ \\
Qual tipo de especialização profissional & & $15,40 \%$ \\
Saúde coletiva & 7 & $30,76 \%$ \\
Saúde da família & 2 & $23,07 \%$ \\
Urgência e emergência & 4 & $15,40 \%$ \\
Unidade de terapia intensiva (UTI) & 3 & $7,69 \%$ \\
Obstetrícia & 2 & $7,69 \%$ \\
Metodologia do ensino & 1 & $\mathbf{1 5 3 , 8 6 \%}$ \\
Políticas públicas & 1 & \\
Total & $\mathbf{2}$ & \\
& $\mathbf{0}$ & \\
& &
\end{tabular}




\begin{tabular}{llc} 
Sexo & 1 & \\
Feminino & 3 & $100 \%$ \\
Total & $\mathbf{1}$ & $\mathbf{1 0 0 \%}$ \\
& $\mathbf{3}$ & \\
Tempo de formação (anos) & & \\
$1-3$ & 1 & $7,69 \%$ \\
$3-5$ & 5 & $38,50 \%$ \\
$5-10$ & 3 & $23,07 \%$ \\
$10-15$ & 2 & $15,38 \%$ \\
$20-25$ & 1 & $7,69 \%$ \\
25 ou mais & 1 & $7,69 \%$ \\
Total & $\mathbf{1 3}$ & $\mathbf{1 0 0 \%}$ \\
Tempo de atuação no serviço (anos) & & \\
Menos de 1 ano & 1 & $7,69 \%$ \\
$1-3$ & 5 & $38,50 \%$ \\
$3-5$ & 1 & $7,69 \%$ \\
$5-10$ & 3 & $23,07 \%$ \\
$10-15$ & 1 & $7,69 \%$ \\
$15-20$ & 2 & $15,38 \%$ \\
Total & $\mathbf{1 3}$ & $\mathbf{1 0 0 \%}$ \\
\hline
\end{tabular}

Fonte: Dados primários elaborados pelos autores

O presente estudo também buscou identificar o grau de conhecimento sobre o tema violência dos enfermeiros da AB. Segundo os dados levantados $92 \%$ dos participantes expressaram ter tido o tema violência abordado na graduação (gráfico 1), em contrapartida apenas $23 \%$ já participaram de curso ou palestra que abordassem a violência contra a gestante (gráfico 2). 
Gráfico 1: Tema violência abordado na graduação

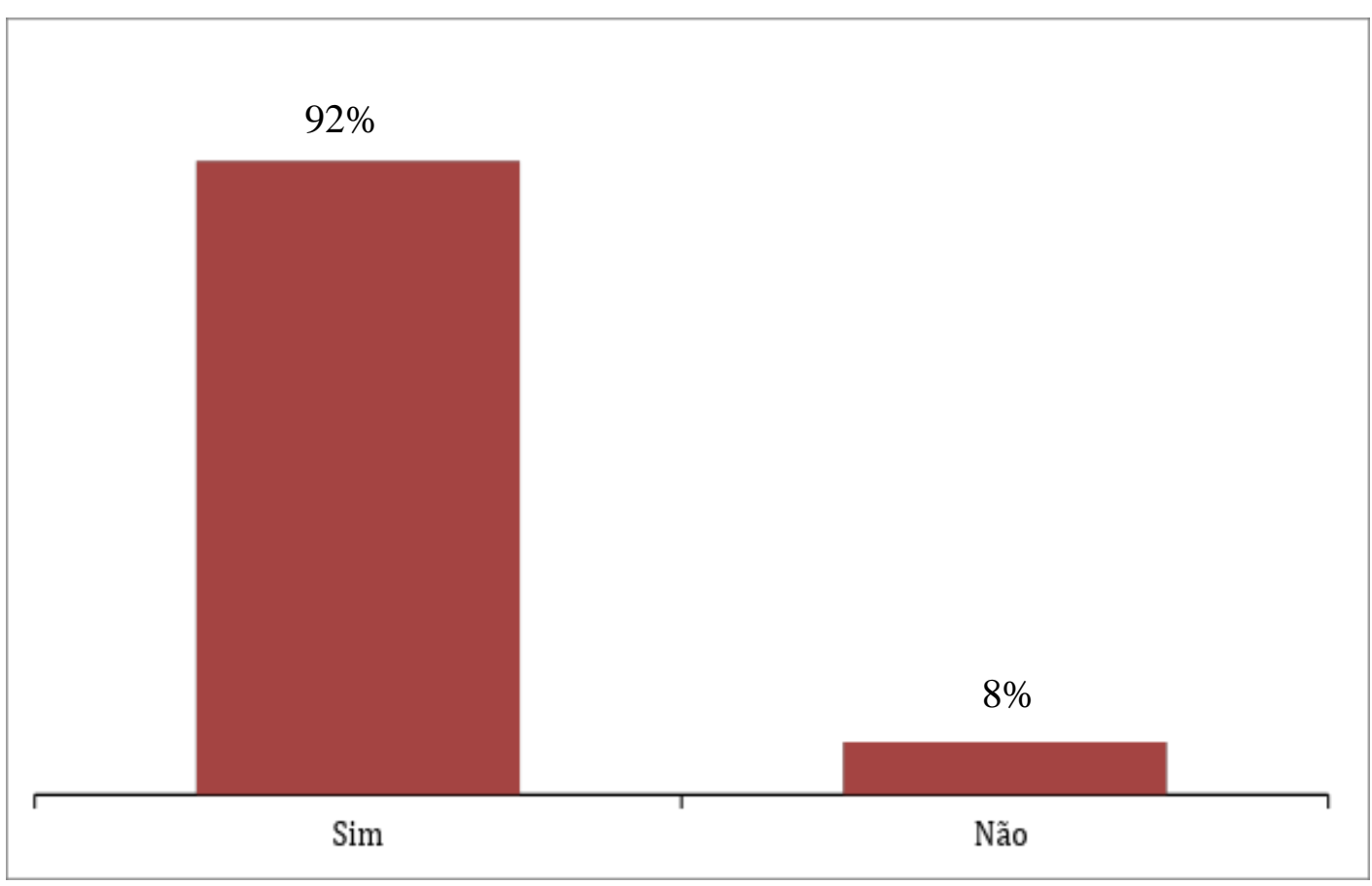

Fonte: Dados primários elaborados pelos autores

Gráfico 2: Participação em curso ou palestra sobre violência contra a gestante

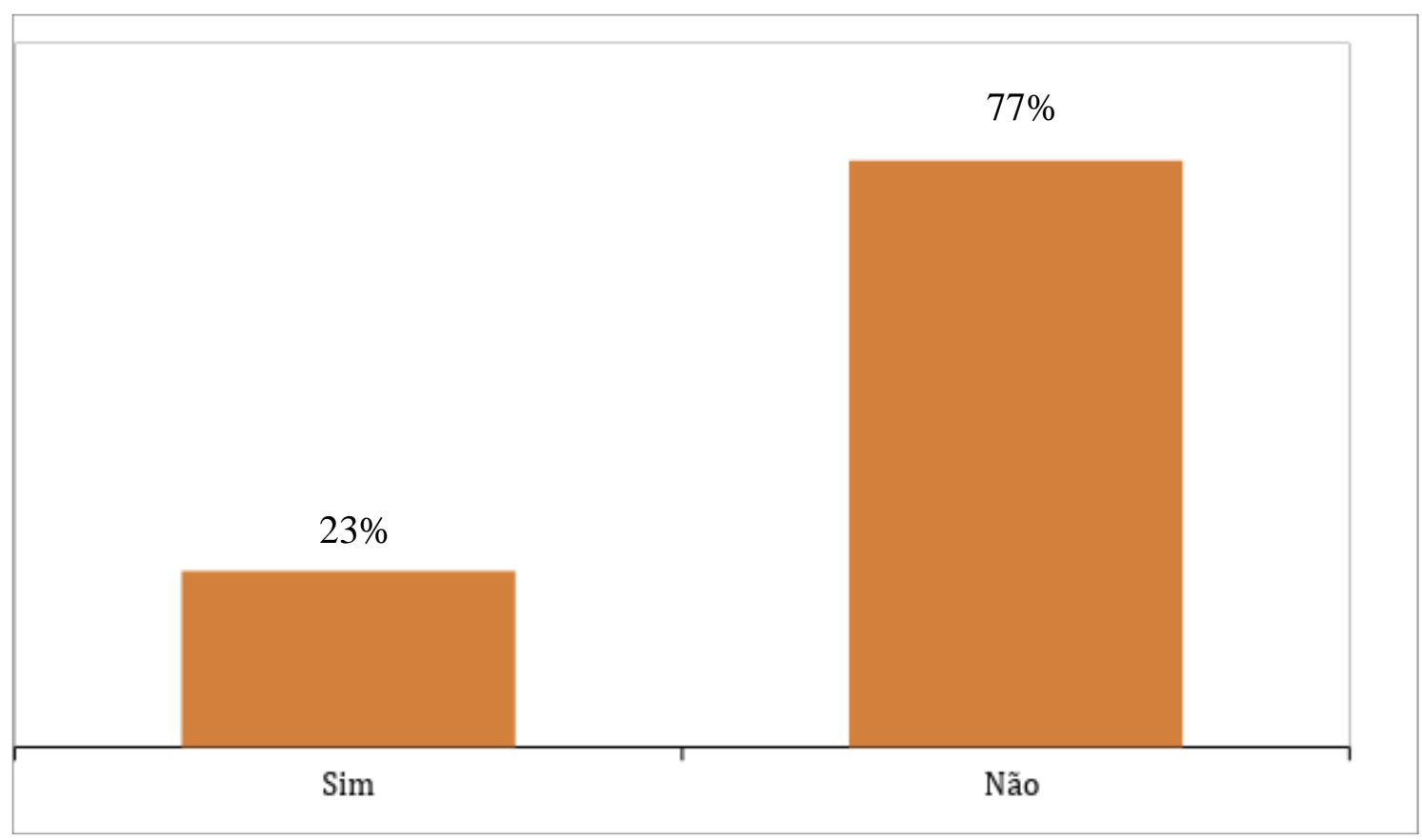

Fonte: Dados primários elaborados pelos autores

1209 Id on Line Rev. Mult. Psic. V.13, N. 47 p. 1202-1219, Outubro/2019 - ISSN 1981-1179 Edição eletrônica em http://idonline.emnuvens.com.br/id 
Outro elemento investigado foram os enfoques dados nos cursos ou palestras sobre o enfrentamento da violência, na qual foram abordados os temas: Violência obstétrica, violência perpetrada pelo parceiro e feminicídio em proporções iguais (gráfico 3).

Gráfico 3: Enfoques dos cursos ou palestras sobre enfrentamento da violência contra a gestante

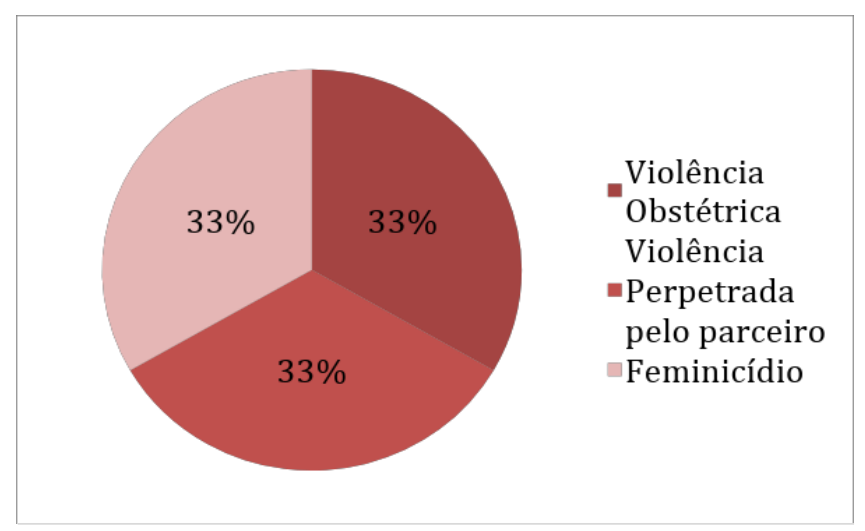

Fonte: Dados primários elaborados pelos autores

\section{Discussão}

\section{O emergir dos eixos temáticos}

A partir das entrevistas semiestruturadas, a análise temática dos dados permitiu a identificação de três eixos temáticos: "Desconhecimento das tipologias de violência", "Notificação e conduta dos casos suspeitos" e "Trabalho em rede". Uma vez identificados estes eixos empíricos, foram "recortadas" as falas, e agrupadas de acordo com seu conteúdo e significado, que pautaram as discussões.

\section{Desconhecimento das tipologias de violência}

A violência, em seu sentido amplo, se tornou um fenômeno social de ampla atuação, não é, portanto, um fenômeno criado na contemporaneidade, mas tem-se falado cada vez mais da violência, e realizado um esforço de definir e/ou conceituar para conhecimento e enfrentamento acerca da mesma. ${ }^{24}$ 
Os enfermeiros participantes do estudo conceituaram violência de acordo com as suas concepções e experiências mais corriqueiras, conforme se verificou nos discursos a seguir:

“[...]A violência física quando a gente está falando de uma paciente que ela é espancada em casa, mas existe também a psicológica que ela sofre muito na gestação [...]". (E3) "Violência não só é física, pode ser verbal também né? Que agrida tanto ela como mulher, quanto o psicológico"'.(E4)

“[...] A violência física, mas eu acho que a maior é a violência verbal, é a questão da falta de respeito". (E7)

No que se refere às tipologias de violência utilizada pela Lei Maria da Penha, apresentada em cinco formas de violência de gênero pelo Art. $7^{\circ}$, os enfermeiros abordam a violência física e a psicológica, deixando de contemplar a moral, a patrimonial e a sexual, que são também de grande impacto social. ${ }^{11}$

A violência moral tem forte conexão com a violência psicológica, pois esta também traz danos psicológicos, por se configurar como qualquer conduta ou ato que gere calúnia, difamação ou injúria a mulher, devido sua invisibilidade. Assim como a patrimonial, caracterizada, por exemplo, pela negação de pensão alimentícia por parte do cônjuge. Tipologia bem frequente, mas não há os devidos conhecimentos sobre a mesma.

E a violência sexual que é considerada uma demonstração extrema de poder do homem sobre as mulheres que se configura como uma forma de violência física e psicológica de modo simultâneo. ${ }^{25}$

Outra vertente bastante abordada pelos enfermeiros foi à VO, na qual denota uma fragilidade no processo de educação em saúde com as gestantes por parte dos profissionais, estratégia essa, importante para o empoderamento da parturiente.

"[...] A violência obstétrica, a mulher não pode escolher a posição de parir, não pode escolher o acompanhante. Quando chega sentindo as dores é refém de piada. Enfim...". (E2).

"[...] Na hora do parto é a que a gente tem mais queixa, da violência física e psicológica que ela passa durante o parto. Com relação a procedimentos como a sondagem vesical até palavras de baixo escalão [...]". (E3)

"[...]No pré-natal, a gente faz todas as orientações, todo um manejo para que ela possa ter um parto tranquilo. E de repente ela chega no puerpério, abordando que foi maltratada, que foi cortada sem necessidade, que foi machucada, insultada com palavras, ai isso é muito triste'.(E5)

"Tem a questão da episiotomia que às vezes os médicos fazem sem ao menos comunicar a gestante [...]"'. (E9)

Segundo um dossiê elaborado pela Rede Parto do Princípio para a CPMI da Violência Contra as Mulheres, existem alguns tipos de configuração da VO, são eles: 
1) VO física: quando são realizadas práticas invasivas, administra-se medicações não justificadas pelo estado de saúde da parturiente ou de quem irá nascer, ou quando não se respeita o tempo ou as possibilidades de parto biológico; 2) VO psíquica: refere-se ao tratamento desumanizado, grosseiro, humilhação e discriminação. Além disso, cabe nesta classe a omissão de informações sobre a evolução do parto; 3) VO sexual: toda ação imposta à mulher que viole sua intimidade ou pudor, incidindo sobre seu senso de integridade sexual e reprodutiva, podendo ter acesso ou não aos órgãos sexuais e partes íntimas do seu corpo. ${ }^{26}$

Os enfermeiros abordaram também outros tipos de violência: A violência de direitos trabalhistas e de direitos sociais:

\footnotetext{
"Tudo que tira dela o direito, desde as leis que regem um pré-natal de qualidade, uma medicação, vacina. Até quando ela pari, a questão da licença maternidade, o direito de amamentação [...]”. (E5)

"[...] A falta de respeito que se tem com aquela pessoa, por exemplo: Eu tenho uma gestante que estar numa fila em pé e uma pessoa normal não dar o assento a ela, isso é uma violência [...]"'. (E7)
}

O decreto $\mathrm{N}^{\circ}$ 5.452, De $1^{\circ}$ de Maio de 1943, consolidou as leis trabalhistas e dentre elas as especificidades de direitos e deveres das gestantes e das puérperas. Dentre suas propostas coloca em vigor a estabilidade no emprego sendo proibida a demissão sem justa causa desde a confirmação da gravidez até os 5 meses após o parto, licença maternidade de no mínimo 120 dias, direito a amamentação com dois intervalos de trinta minutos em carga laboral de oito horas diária, dispensa do horário de trabalho pelo tempo necessário para realização de, no mínimo, seis consultas médicas e demais exames e serviços de saúde. ${ }^{27}$

Os direitos sociais oferecidos às grávidas foram o resultado de uma luta pelas mulheres desenvolvidos a partir da compreensão e necessidade de proteção à gestante e bebê, sendo eles: atendimento em caixas especiais, prioridades na fila de bancos, supermercados, acesso à porta da frente de transportes públicos e assentos preferenciais. Direitos estes assegurados pela Lei de $\mathrm{n}^{\circ}$ 10.048 de 08 de Novembro de $2000 .^{28}$

\section{Notificação e conduta dos casos suspeitos}

O Ministério da Saúde (MS) incluiu, no ano de 2009, a violência doméstica, sexual e/ou outras violências na listagem de doenças e agravos de notificação compulsória. Desta forma, toda e qualquer suspeita ou confirmação de violência, tanto no serviço de atenção primária quanto no hospitalar, deve ser registrada na Ficha de Notificação e Investigação (FNI). ${ }^{29}$ 
De acordo com a proposta do presente estudo foi realizado um levantamento na base de dados do SINAN, a respeito do número de notificações de violência contra a mulher a partir do ano de 2014 até junho de 2018. Nota-se grande avanço no número de notificações sendo: 2014 com 04 casos notificados, 2015 com 10 casos, 2016 com 04 casos, 2017 com 26 casos, 2018 com 40 casos. O aumento do número de notificações, justifica-se este aumento pela implantação da Lei Maria da Penha e do Feminicídio, que reforçou a importância da notificação pelos profissionais.

Outro fator observado foi a unidade notificadora dos casos de Janeiro até Novembro do ano de 2018. Foi visto que do total de 40 notificações apenas 01 foi realizada pela ESF do município, enquanto que 33 notificações foram realizadas pelo Hospital municipal, demonstrando a fragilidade do profissional Enfermeiro em notificar os casos suspeitos na atenção primária.

Verificou-se a impotência diante da ação de notificar o evento por medo de represálias por parte do agressor:

\footnotetext{
"Como a gente é uma pessoa que trabalha na ponta, eu não posso medir forças com aquela pessoa que praticou a violência, então no meu papel, eu procuro ajuda, entendeu?" (E7)

"[...] Nunca cheguei a denunciar porque nunca foi confirmado nem solicitado por parte da gestante esse tipo de abordagem." (E6)
}

Em 2004, foi criada a portaria ${ }^{\circ} 2.406$ que instituiu o serviço de notificação compulsória de violência contra a mulher, aprovando o instrumento e fluxo para notificação. ${ }^{30}$

Identificou-se posteriormente lacunas nas falas dos Enfermeiros quanto ao uso de um fluxograma para nortear os passos a serem seguidos nos casos suspeitos:

“[...] a gente não tem nada, um formulário, uma rotina de notificação, mas a gente tem que conseguir". (E7)

" $[. .$.$] normalmente quando acontece, a gente vai tentar desenrolar, mas um fluxograma$ pré-estabelecido não tem não, deve ter no livro que a gente aplica pra fazer o pré-natal, mas graças a Deus eu não tenho procurado por ele não". (E12).

Diante dos discursos apresentados observa-se que estas práticas influenciam para ocorrência de subnotificações, silenciando a violência das vítimas.

Estudo realizado em 2017 com profissionais de Enfermagem a respeito das condutas frente à violência mostrou que dentre os motivos que resultam na subnotificação, destacam-se: o medo dos profissionais em relação a se expor e sofrer represálias por parte dos agressores, a crença de que o que acontece no ambiente familiar deve se restringir a esse ambiente (e não ao meio social), o descaso por parte das autoridades públicas, como também o fato de que os profissionais não recebem retorno das medidas adotadas, o que faz com que acreditem que não vale a pena notificar, contribuindo para o sentimento de fracasso de sua parte perante essas situações. ${ }^{14}$ 
Percebendo a importância e relevância de que as questões de gênero estejam inseridas nas políticas públicas, os profissionais dos serviços de atendimento assumem um papel preponderante diante das circunstâncias da violência, pois a sua atuação e responsabilidade não se reduz a uma questão técnica, configurando-se também como uma prática social importante para o combate da desigualdade de gênero e efetivação dos direitos das mulheres. ${ }^{31}$

Quanto às demais condutas diante dos casos suspeitos, os enfermeiros demonstraram conhecimento sobre sua responsabilidade, porém referem em seus discursos a escolha em transferir os casos para outros profissionais:

\footnotetext{
"A conduta é a gente escutar a gestante, naquele jeito bem sigiloso e encaminha para a psicóloga do NASF." (E3)

"Falo sobre a importância de denunciar, de não se calar e que não é admissível, ainda mais nas condições em que ela se encontra, por estar gestando uma criança.” (E6)

"Eu sempre faço orientação e seguidamente tem um NASF aqui, sempre procuro apoio com a psicóloga." (E13)
}

Por parte dos profissionais, há um despreparo sobre a forma de abordagem à vítima e a sistematização da assistência, que se deve principalmente à escassez de protocolos específicos, fluxogramas, que abordem parâmetros técnicos e científicos para a condução da prática assistencial e encaminhamentos. ${ }^{32}$

É primordial que os profissionais responsáveis pelos atendimentos às mulheres vítimas de violência reconheçam seu papel frente aos casos e o exerçam de forma correta para que seja assegurado um cuidado que respeite e atenda as necessidades da vítima, evitando posturas resistentes das mesmas quanto ao reconhecimento deste processo.

\section{Trabalho em rede}

Destaca-se que, para lidar com casos de violência, a rede de assistência em saúde é o modelo mais aceito pela literatura, e nela, "a entrada pode se dar em qualquer ponto, sendo a circulação dos casos um trançamento entre os diversos pontos desse conjunto (os distintos serviços), entre os quais não há hierarquia de disposição e sim uma colocação horizontal nas relações entre si. ${ }^{33}$

Os Enfermeiros demonstram em seu discurso um escasso conhecimento quanto a existência de uma rede de serviços na assistência aos casos de violência, justificado pelo fato de não vivenciarem casos em sua rotina de trabalho:

\footnotetext{
"Eu acho até que existe, só que nunca tomei conhecimento e também nunca me aconteceu casos. É um tema que tanto no município como em outros, precisa ser mais reconhecido.', (E5)
} 
“Até agora eu não ouvi falar, mas acredito que se houver violência, tem que ter alguma coisa. Ninguém vai deixar passar em branco."’(E2)

Dentre os pesquisados que apresentaram algum conhecimento sobre o processo de trabalho em rede, os profissionais da equipe do Núcleo de Apoio a Saúde da Família (NASF), Psicólogo e assistente Social foram os mais presentes nas falas:

"Tenho a suspeita, eu encaminho pra NASF, psicólogo, assistente social, pra gente chegar a uma conclusão." (E12)

"Tem um NASF aqui, sempre procuro apoio com a psicóloga.” (E13)

O Nasf deve apoiar as equipes da ESF para identificar e fortalecer ou incentivar a criação de uma rede de atenção à mulher vítima de violência, que deve ser estruturada nos municípios, envolvendo, por exemplo, as Delegacias Especiais da Mulher, Casas de abrigo, Conselho da Mulher, Comissões municipais e hospitalares de atendimento à mulher vítima de violência etc. $\mathrm{O}$ Nasf deve apoiar as equipes de ESF no reconhecimento dos casos de violência e atendimento a eles, dentro de sua capacidade estrutural. ${ }^{34}$

O Centro de Referência de Assistência Social (CRAS) e o Centro de Atendimento Especializado da Assistência Social (CREAS), também obtiveram destaque nas falas como dispositivos da rede acionados segundo os entrevistados:

"A gente orienta o pessoal a ir no CRAS ou no CREAS ." (E7)

"[...] a gente tem o pessoal do CRAS, e com eles sabemos mais ou menos o roteiro que tem que seguir." (E12)

O CRAS é uma unidade de proteção social básica, que visa prevenir a ocorrência de situações de vulnerabilidades e riscos sociais nos territórios, por meio do fortalecimento de vínculos familiares e comunitários, e da ampliação do acesso aos direitos de cidadania. ${ }^{35}$

O CREAS é uma entidade governamental, estabelecida pelo Sistema Único de Assistência Social (SUAS), que presta atendimento especializado às vítimas de violência. ${ }^{36}$

A delegacia e a coordenadoria da mulher também se fizeram presente na fala dos Enfermeiros como dispositivos para a proteção e medidas legais da rede de assistência à vítima:

\footnotetext{
"Encaminhamos a gestante pra delegacia, pra prestar o B.O." (E10)

"[...] A gente tem a coordenadoria da mulher que tem um trabalho no município [...]". (E6)

“[...] A gente sempre trabalha nos PSF's e na coordenadoria da mulher, eles sempre abordam esse tema com relação a gestante né. Inclusive agora a gente tem uma parceria com a coordenadoria onde a gente encaminha diretamente essas pacientes [...].” (E5)
} 
As Delegacias Especializadas de Atendimento às Mulheres (DEAMS), bem como os demais serviços de proteção para este público são um marco na luta feminista: elas materializam o reconhecimento da violência contra mulheres como um crime e implicam a responsabilização do Estado no que se refere à implantação de políticas que permitam o combate a esse fenômeno. ${ }^{37}$

As Coordenadorias e as Secretarias de Políticas para Mulheres nos Estados e/ou nos municípios cumprem função primordial no apoio à atuação das delegacias como articuladoras da rede.

Destaca-se que no município que foi realizado o estudo ainda não há uma Deams implantada, uma vez que pelo critério de número absoluto da população, o mesmo ainda não se enquadra como elegível para receber uma. Portanto, toda demanda referente aos casos de violência contra a mulher devem ser resolvidas na delegacia municipal. ${ }^{38}$

\section{Conclusões}

Este trabalho buscou conhecer como os profissionais da ESF reconhecem e enfrentam o fenômeno da violência contra as mulheres grávidas. Desse modo, observou-se que, apesar de grande parte da amostra referir ter trabalhado a temática na graduação, e outra parcela ter visto em capacitações e formações, ainda é incipiente o preparo dos profissionais para o correto manejo diante dos casos de violência contra a gestante, tendo em vista que, grande parte dos enfermeiros, não reconhecem todas as tipologias, não se sentem capazes em realizar a notificação, não tem conhecimento sobre os significados do trabalho em rede, bem como dos serviços que a compõe.

Ressalta-se a importância do trabalho em rede e do reconhecimento dos demais serviços como dispositivos fortalecedores para assegurar um correto e devido desfecho dos casos de violência identificados, bem como a necessidade dos mecanismos de referência e contra referência, assegurando o real sentido do trabalho em rede.

Não obstante, destaca-se a necessidade de sensibilizar e qualificar os Enfermeiros a identificar e abordar qualquer tipo de violência, além de encorajá-los a promover educação em saúde no intuito de instruir as gestantes dos tipos e formas de violência para que assim o fenômeno da violência seja enfrentado de maneira eficaz, promovendo a prevenção de violências futuras, empoderando este público e contribuindo para as discrepâncias de gênero existentes na sociedade. 


\section{Referências}

1. Sousa GM de, Damasceno KCF, Borges L de CF. Estratificação dos tipos de violência notificados pelo SINAN, no município de Porto Nacional, TO, em 2014. Rev Interface. 2016 maio; (11): 34-45.

2. Pires MRGM, Silva LVS, Fonseca RMGS, Oliveira RNG, Gessner R, Gouveia E de P. Violetascinema\&ação no enfrentamento da violência contra a mulher:concepção de subjetividade, gênero, cidadania e ludicidade nas regras e nas cartas do jogo. Rev Interdisciplinar em Cultura e Sociedade. 2017 jan./jul; 3(esp): 99-115.

3. Teixeira SVB, Moura MAV, Silva LR, Queiroz ABA, Souza KV, Netto LA. Violência perpetrada por parceiro íntimo à gestante: o ambiente à luz da teoria de Levine*. Rev Esc Enferm USP. 2015; 49(6): 882-9.

4. Brasil. Ministério da saúde. Sistema de Informação sobre Mortalidade (SIM). Óbitos de mulheres por causas externas. Disponível em: http://tabnet.datasus.gov.br/cgi /deftohtm.exe?idb2011/c09.def

5. Leal SYP, Lima VL de A, Silva AF, Soares PDFL, Santana LR, Pereira A. Percepção de enfermeiras obstétricas acerca da violência obstétrica. Cogitare Enferm. 2018; 2(23).

6. Garcia-Moreno C, Jansen HA, Ellsberg M, Heise L, Watts CH. Prevalence of intimate partner violence: findings from the WHO multi-country study on women's health and domestic violence. 2006 oct; 368(9543): 1260-9.

7. Carneiro JF, Valangueiro S, Ludermir AB, Araújo TVB de. Violência física pelo parceiro íntimo e uso inadequado do pré-natal entre mulheres do Nordeste do Brasil. Rev bras epidemiol. 2016 abr-jun; 19(2): 243-255.

8. Jesmin SS. Social Determinants of Married Women's Attitudinal Acceptance of Intimate Partner Violence. Journal of Interpersonal Violence. 2015; 32(21): 3226-3244.

9. Oliveira LCQ de, Fonseca-Machado M de O, Stefanello J, Gomes- Sponholz FA.Violência por parceiro íntimo na gestação: identificação de mulheres vítimas de seus parceiros. Rev. Gaúcha Enferm. 2015; 36(esp): 233-8

10. Salcedo-Barrientos DM, Miura PO, Macedo VD, Egry EY. Como os profissionais da Atenção Básica enfrentam a violência na gravidez?. Rev. Latino-Am. Enfermagem. 2014 maio-jun; 22(3) 448-53.

11. Brasil. Lei Maria da Penha: Lei n ${ }^{\circ}$ 11.340. Brasília: Secretaria Especial de Políticas para Mulher, 2006. Disponível em: http://www.planalto.gov.br/ccivil_03/_ato20042006/2006/lei/111340.htm

12. Brasil Lei do Feminicído. Lei $\mathrm{n}^{\circ}$ 13.104, de 9 de março de 2015. Disponível em: http://www.planalto.gov.br/ccivil_03/_ato2015-2018/2015/lei/L13104.htm

13. Martins L de CA, Silva EB da, Dilélio AS, Costa MC da, Colomé IC, dos S, Arboit J. Violência de gênero: conhecimento e conduta dos profissionais da estratégia saúde da família. Rev Gaúcha Enferm. 2018; 39:e 2017-0030.

14. Silvino MCS, Silva LFF, Duartes SCF, Belantini L, Oliveira MLF de. Mulheres e Violência: Características e Atendimentos Recebidos em Unidades de Urgência. J Health Sci. 2016; 18(4): 240-4.

15. Galindo NA de L, Gonçalves CFG, Neto NMG, Santos SC dos, Santana CSC, Alexandre ACS. Violência infanto-juvenil sob a ótica da enfermagem. Rev enferm UFPE on line. 2017 mar; 11(3):1420-9.

16. Gil, AC. Como elaborar projetos de pesquisa. 5. ed. São Paulo: Atlas, 2010.

17. Minayo, MCS. O Desafio do Conhecimento: Pesquisa Qualitativa em Saúde. 12. ed. São Paulo: Hucitec; 2010. 
18. IBGE. Instituto Brasileiro de Geografia e Estatística. Cidades. Pesqueira-PE. Disponível em: https://cidades.ibge.gov.br/xtras/perfil.php?codmun $=261090$

19. CNES. Cadastro Nacional de Estabelecimentos em Saúde. Disponível em: http://www.cnes.datasus.gov.br/

20. Bardin, L. Análise de conteúdo (L. de A. Rego \& A. Pinheiro, Trads.). Lisboa: Edições 70; 2006

21. Marconi MA, Lakatos EM. Fundamentos de metodologia científica. 7. ed. São Paulo: Atlas; 2010.

22. Brasil. DATASUS. Departamento de Informática do SUS. Disponível em: http://datasus.saude.gov.br/datasus.

23. Brasil. Conselho Nacional de Saúde. Resolução n 466, de 12 de dezembro de 2012. Aprova normas regulamentadoras de pesquisas envolvendo seres humanos. Brasília: Diário Oficial da União, 2012.

24. Silva MDR, Violência contra a mulher: analise da Lei Maria da Penha e suas implicações no município de Codó-Maranhão 2006-2017 [monografia]. Codó: Universidade Federal do Maranhão Campus Codó; 2018.

25. Delzivo CR, Bolsoni CC, Nazaré NO, Coelho EBS. Características dos casos de violência sexual contra mulheres adolescentes e adultas notificados pelos serviços públicos de saúde em Santa Catarina, Brasil. Cad. Saúde Pública [online]. 2017; 33(6).

26. Pereira JS, Silva JC de O, Borges NA, Ribeiro M de MG, Auarek LJ, Souza JHK de. Violência obstétrica: ofensa à dignidade humana. BrazilianJournal of Surgery and Clinical ResearchBJSCR. 2016 jun-ago; 15(1): 103-8.

27. Brasil. Decreto n. ${ }^{\circ}$ 5.452, De $1^{\circ}$ de Maio de 1943. Diário Oficial [da] República Federativa do Brasil. 1943 mai.1. [Acesso em 2018 nov 20]. Disponível em: http://www.planalto.gov.br/ccivil_03/Decreto-Lei/Del5452.htm

28. Brasil. Presidência da República, Subchefia para Assuntos Jurídicos. Lei no 10.048 de 08 de Novembro de 2000. Dá prioridade de atendimento às pessoas que especifica, e dá outras providências [Internet]. Brasília, DF; 2000. [acesso em 2018 nov 20]. Disponível em:http://www2.camara.leg.br/legin/fed/lei/2000/lei-10048-8-novembro-2000-376937normaatualizada-pl.html

29. Belentani L, Sartorelli ACM, Meschial WC, Lima MF, Oliveira MLF. Violência Contra Crianças, Adolescentes e Mulheres: Desfecho de casos atendidos em um Hospital Ensino. Rev Enferm UFSM [Internet]. 2012 Jan/Abr; 2(1):10-9.

30. Brasil. Ministério da Saúde. Portaria $n^{\circ}$ 2.406, de 5 novembro de 2004. Institui serviço de notificação compulsória de violência contra a mulher nos serviços de saúde, e aprova instrumento e fluxo para notificação. Diário Oficial da União, 2004 nov. 9; Seção 1. p 84.

31. Cortes GR, Alves EC, Silva LKR da. Mediação da informação e violência contra mulheres: disseminando a informação estatística no Centro Estadual de Referência da Mulher Fátima Lopes. In: Encontro Nacional de Pesquisa em Ciência da Informação, 2015; João Pessoa.

32. Andrade JO, Castro SS, Heitor SFD, Andrade WP, Atihe CC. Indicadores da violência contra a mulher provenientes das notificações dos serviços de saúde de Minas Gerais-Brasil. Texto Contexto Enferm. 2016; 25(3): 1-9.

33. Cortes LF, Padoin SMM, Kinalski DDF. Instrumentos para articulação da rede de atenção às mulheres em situação de violência: construção coletiva. Rev Gaúcha Enferm. 2016; 37(esp): 2016-0056.

34. Brasil. Ministério da Saúde. Portaria n ${ }^{\circ} 154$ de 24 de janeiro de 2008. Cria os Núcleos de Apoio à Saúde. Diário Oficial da Republica Federativa do Brasil, Brasília, DF, 2008.

35. BRASIL. Centro de Referência de Assistência Social. Ministério do Desenvolvimento Social e Combate à Fome. Brasília, DF, 2009; ed 1. p 72. 
36. Faraj GR, Siqueira AC. O atendimento e a rede de proteção da criança e do adolescente vítima de violência sexual na perspectiva dos profissionais do CREAS. Rev do dep de Ciências Humanas. 2012 jul/dez; (37): 67-87.

37. Souza L de, Cortez MB. A Delegacia da Mulher perante as normas e leis para o enfrentamento da violência contra a mulher: um estudo de caso. Rev. Adm. Pública. 2014 mai/jun; 48 (3): 621639.

38. Brasília. Ministério da Justiça. Norma técnica de padronização das delegacias especializadas de atendimento as mulheres- DEAMs. 2010. Disponível em: http://www.spm.gov.br/lei-maria-dapenha/lei-maria-da-penha/norma-tecnica-de-padronizacao-das-deams-.pdf

\section{Como citar este artigo (Formato ABNT):}

SANTOS, Julliany Larissa Correia; RODRIGUES, João Victor Silva; LEITE-SALGUEIRO, Claudia Daniele Barros; GONÇALVES, Cláudia Fabiane Gomes; ALMEIDA, Taysa Vieira; SOARES, Gladyanny Costa Veras. Percepção dos Enfermeiros da Atenção Primária diante da Violência Contra a Gestante. Id on Line Rev.Mult. Psic., Outubro/2019, vol.13, n.47, p. 1202-1219. ISSN: 1981-1179.

Recebido: 23/10/2019

Aceito: 29/10/2019. 